\title{
18th Century Eye Testing Spectacles
}

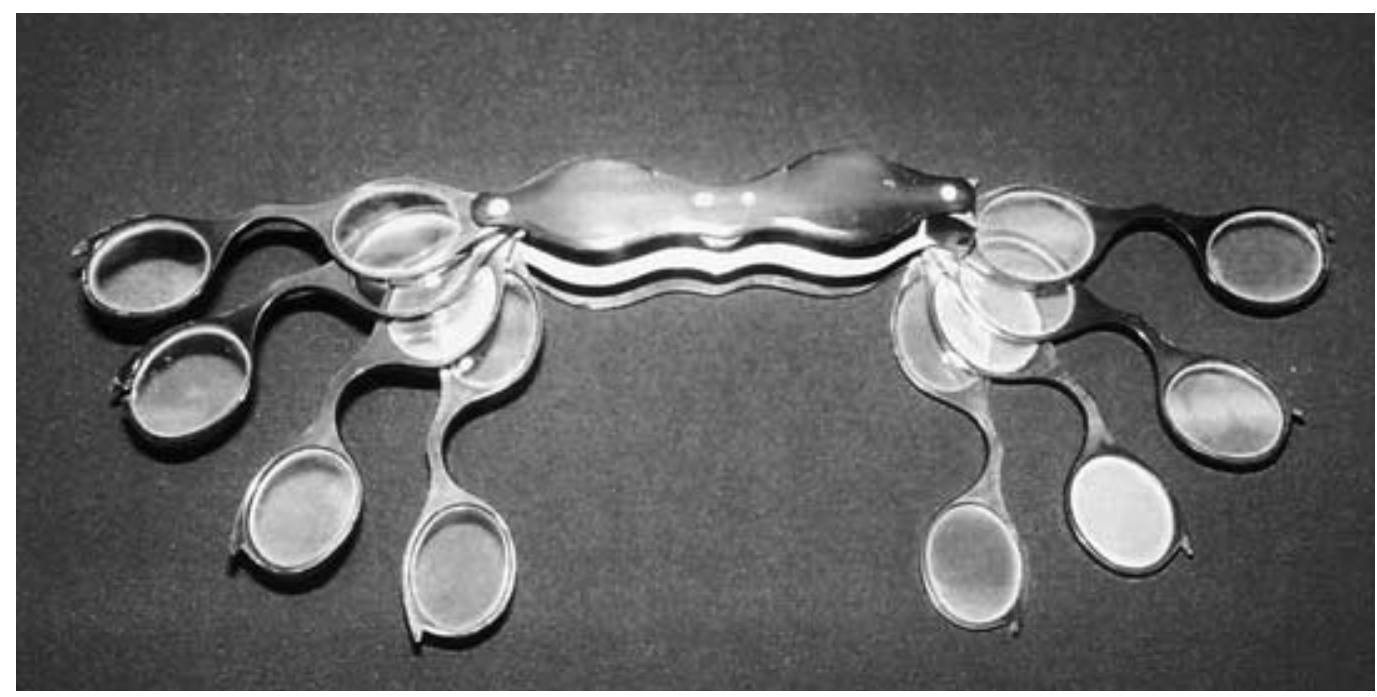

It is believed that spectacles were discovered in the early 14 th century, most probably by Armati of Florence.

The testing spectacles illustrated were the property of Pierre de Sales La Terriere of Trois Riviers, Quebec, Canada. He studied medicine in Canada and subsequently at St Thomas's Hospital, where he became
MRCS. He previously served as a Surgeon in the Voltigeure Canadiens, during the war of 1812. Whilst at St Thomas's, he attended wounded from the Peninsular Wars.

These spectacles were purchased at auction.

PH Starling Curator AMS Museum 